\title{
Pengaruh Lingkungan Keluarga terhadap Penyalahgunaan NAPZA pada Remaja
}

\author{
Dwi Oktavia Sri Asmoro, Soenarnatalina Melaniani \\ Departemen Biostatistika dan Kependudukan FKM UNAIR \\ Fakultas Kesehatan Masyarakat Universitas Airlangga \\ J1. Mulyorejo Kampus C Unair Surabaya 60115 \\ Alamat korespondensi: \\ Dwi Oktavia Sri Asmoro \\ E-mail:dwioktavia_sriasmoro@yahoo.com
}

\begin{abstract}
The number of drug users was increasing. Drug abuse is regarded as one. Drug user regarded as a threat that sooner or later can destroy the young generation. The research was aimed to analized the influence of family environmental factors toward to abuse juvenile drug in Surabaya. The research was observational research by design cross sectional. Technique sampling was simple random sampling, with sampling teenager was 10-19 year drug users who performs outpatient in BNN throughout Surabaya as many as 53 people. The study was done at December 2015. This research used obtained through primary and secondary data, the analysis used binary regression logistic techniques. The study results show that the influence of family environment that is harmonious family $\left(p_{\text {value }}=0,026\right.$; or $\left.=6,179\right)$, bustle parents $\left(p_{\text {value }}=0,032\right.$; or $\left.=5,677\right)$, parents permissive $(p=0.015$; or $=8,001)$, Religious in the family $\left(p_{\text {value }}=\right.$ much as $0.021 ;$ or $\left.=6,401\right)$ and religious in the family are the influence on the environment factors ( $p_{\text {value }}=0.021$; or $\left.=6,401 ; C I=1,321-31,025\right)$. Religious in the family are the most influence in the family environment factors. It was recommended parents need to create family bonds strong via relationship emotional and taste emphatic on child.
\end{abstract}

Keywords: family environment, drug abuse, teenager

\begin{abstract}
ABSTRAK
Jumlah pengguna napza pada remaja semakin meningkat dari tahun ke tahun. Penyalahguna napza dianggap sebagai suatu ancaman yang cepat atau lambat dapat menghancurkan generasi muda karena dapat memberikan dampak penurunan moralitas dan meningkatnya tindak pidana. Penelitian ini dilakukan untuk menganalisis pengaruh faktor lingkungan keluarga terhadap penyalahgunaan napza pada remaja di Surabaya. Penelitian ini merupakan penelitian observasional dengan desain cross sectional. Teknik sampling pada penelitian ini adalah simple random sampling, dengan sampel remaja berusia 10-19 tahun pengguna NAPZA yang melakukan rawat jalan di BNN Kota Surabaya sebanyak 53 orang. Penelitian ini dilakukan pada bulan Desember 2015. Sumber data dalam penelitian ini diperoleh melalui data primer dan data sekunder dan teknik analisis yang digunakan adalah regresi binari logistik. Hasil penelitian menunjukkan adanya pengaruh pada lingkungan keluarga yaitu keharmonisan keluarga $\left(\mathrm{p}_{\text {value }}=\right.$ $0,026 ; \mathrm{OR}=6,179)$, kesibukan orang tua $\left(\mathrm{p}_{\text {value }}=0,032 ; \mathrm{OR}=5,677\right)$, orang tua permisif $\left(\mathrm{p}_{\text {value }}=0,015 ; \mathrm{OR}=\right.$ $8,001)$, ibadah dalam keluarga $\left(\mathrm{p}_{\mathrm{value}}=0,021 ; \mathrm{OR}=6,401\right)$ sedangkan yang paling dominan berpengaruh dari faktor lingkungan keluarga terhadap penyalahgunaan NAPZA pada remaja adalah ibadah dalam keluarga $\left(\mathrm{p}_{\mathrm{value}}=0,021\right.$; $\mathrm{OR}=6,401 ; \mathrm{CI}=1,321-31,025)$. Ibadah dalam keluarga paling berpengaruh pada faktor lingkungan keluarga. Rekomendasi yang dapat di sampaikan dari hasil penelitian Orang tua perlu menciptakan ikatan keluarga yang kuat melalui hubungan emosional dan rasa empatik pada anak.
\end{abstract}

Kata kunci: lingkungan keluarga, Penyalahguna NAPZA, Remaja

\section{PENDAHULUAN}

Penyalahguna NAPZA di Indonesia masih banyak melibatkan pada kalangan remaja, hal ini menyebabkan salah satu ancaman yang dapat menghancurkan generasi muda, dibuktikan dengan semakin meningkatnya tindak pidana (Waluyo B, 2011).
Pengguna NAPZA di Indonesia semakin meluas di kalangan anak usia sekolah, sehingga bila tidak segera diatasi maka dapat menjadi salah satu ancaman bagi kesejahteraan generasi yang akan datang, di mana generasi muda merupakan penerus bangsa dan juga merupakan sumber daya manusia bagi 
pembangunan yang perlu dilindungi (BNN, 2012).

Kaum remaja menjadi penyalahguna NAPZA karena masa remaja merupakan masa transisi dari masa anak-anak ke masa dewasa. Periode ini dianggap sangat penting dalam kehidupan seseorang khususnya dalam pembentukan kepribadian. Masa transisi inilah yang menjadikan emosi seseorang kurang stabil (Yusuf, 2009).

Hasil survey nasional yang tentang penyalahgunaan dan pengedaran gelap NAPZA dari 33 provinsi di Indonesia tahun 2012 menunjukkan bahwa pelajar dan mahasiswa tidak terlepas dari risiko penyalahgunaan NAPZA. Jawa timur merupakan provinsi dalam tiga tahun terakhir masih menempati urutan pertama jumlah kasus NAPZA. Hasil survey di Surabaya menunjukkan tahun 2012 penyalahguna NAPZA pada usia 10-19 tahun sebanyak 15 (2\%), tahun 2013 penyalahguna NAPZA pada usia 10-19 tahun sebanyak 29 orang $(10,5 \%)$, sedangkan pada tahun 2014 penyalahguna NAPZA pada usia 10-19 tahun sebanyak 78 orang (12\%), sehingga dapat disimpulkan setiap tahun menunjukkan adanya peningkatan penyalahgunaan NAPZA pada remaja.

BNN Kota Surabaya merupakan Lembaga Pemerintah Non Kementerian (LPNK) yang berada di Surabaya. BNN Kota Surabaya bertugas melakukan penyelidikan dan penyidikan penyalahgunaan dan peredaran gelap narkotika dan juga sebagai salah satu tempat rehabilitasi rawat jalan penyalahguna NAPZA dengan menerapkan metode konseling.

Penyalahgunaan NAPZA dapat disebabkan salah satunya karena faktor lingkungan keluarga. Keluarga merupakan unit terkecil dalam suatu masyarakat. Penyebab penyalahgunaan NAPZA pada lingkungan keluarga salah satunya yaitu karena keharmonisan (Depkes, 2001).

Peran keluarga sangat penting bagi seorang anak karena keluarga mempunyai kewajiban dalam memberikan pendidikan dan pembentuk karakter pada anak (Sudarsono, 2004). Keutuhan dalam keluarga juga dapat berpengaruh terhadap psikologis seorang anak, sehingga apabila psikologis anak terganggu maka anak akan lebih mudah lari dalam pergaulan negative $\mathrm{di}$ luar rumah dan anak juga akan mudah terjerumus dalam penyalahgunaan NAPZA (Hawari, 2009).

Dampak penyalahgunaan NAPZA bagi penggunanya adalah dapat merasakan kecemasan yang luar biasa, paranoid, delusi formikasi, berperilaku agresi, memiliki nafsu seksual yang tinggi, dan timbulnya berbagai penyakit seperti stroke, radang hati, jantung dan sebagainya hingga menimbulkan kematian. Penyalahgunaan NAPZA dapat disimpulkan bahwa NAPZA dapat merusak dan membahayakan bagi generasi muda dalam suatu bangsa khususnya bagi anak-anak dan remaja (Budiarta, 2000).

BNN (2006) mengungkapkan bahwa penyalahgunaan NAPZA terkait dengan tiga faktor. Faktor tersebut yaitu: (1) faktor lingkungan yang mencangkup lingkungan keluarga, lingkungan sekolah, lingkungan masyarakat; (2) faktor individu yang mencakup keinginan mencoba, ingin perhatian, dan ikut tokoh idola; (3) faktor zat yang mencakup ketergantungan fisik dan psikis, kemudahan dalam mendapatkan juga menjadi pemicu penyalahgunaan NAPZA dengan akses internet yang memberikan informasi memperoleh NAPZA, banyak media massa iklan minuman alkohol, rokok serta adanya apotek untuk membeli obat secara mudah sehingga dapat menarik remaja untuk mencoba, dan relatif murah.

Studi pendahuluan yang dilakukan peneliti didapatkan hasil penyalahguna NAPZA pada remaja sebanyak $70 \%$ remaja menggunakan NAPZA disebabkan faktor lingkungan keluarga terutama orang tua, $27 \%$ disebabkan dari faktor individu dan 3\% dari faktor NAPZA itu sendiri. Maka dari itu peneliti tertarik untuk meneliti pengaruh faktor lingkungan terhadap penyalahguna NAPZA di BNN Kota Surabaya.

Tujuan umum dari penelitian ini adalah menganalisis pengaruh faktor lingkungan keluarga (pola asuh orang tua, keharmonisan keluarga, aktivitas orang tua, tipe orang tua dan ibadah dalam keluarga) terhadap penyalahgunaan NAPZA pada remaja

\section{METODE PENELITIAN}

Jenis penelitian merupakan penelitian kuantitatif dengan metode observasional karena tidak memberikan perlakuan pada subjek 
Tabel 2. Hasil Uji Regresi Binari Logistik Berdasarkan Lingkungan Keluarga dan Pemakaian NAPZA Responden di Wilayah BNN Kota Surabaya.

\begin{tabular}{|c|c|c|c|c|c|c|c|}
\hline \multirow{2}{*}{ Lingkungan Keluarga } & \multicolumn{2}{|c|}{ Masih Memakai NAPZA } & \multicolumn{2}{|c|}{ Tidak Memakai NAPZA } & \multicolumn{2}{|c|}{ Total } & \multirow{2}{*}{$\mathbf{P}_{\text {value }}$} \\
\hline & n & $\%$ & $\mathbf{n}$ & $\%$ & $\mathbf{N}$ & $\%$ & \\
\hline \multicolumn{8}{|l|}{ Pola asuh orang tua } \\
\hline Otoriter & 16 & 64,0 & 9 & 36,0 & 25 & 100,0 & \multirow{2}{*}{0,302} \\
\hline Tidak otoriter & 20 & 71,4 & 8 & 28,6 & 28 & 100,0 & \\
\hline \multicolumn{8}{|l|}{ Keharmonisan keluarga } \\
\hline Tidak harmonis & 24 & 77,4 & 7 & 22,6 & 31 & 100,0 & \multirow[t]{2}{*}{0,026} \\
\hline Harmonis & 12 & 54,5 & 10 & 45,5 & 22 & 100,0 & \\
\hline \multicolumn{8}{|l|}{ Aktivitas orangtua } \\
\hline Orang tua sibuk & 24 & 77,4 & 7 & 22,6 & 31 & 100,0 & \multirow[t]{2}{*}{0,032} \\
\hline Orang tua tidak sibuk & 12 & 54,5 & 10 & 45,5 & 22 & 100,0 & \\
\hline \multicolumn{8}{|l|}{ Tipe orangtua } \\
\hline Permisif & 19 & 82,6 & 4 & 17,4 & 23 & 100,0 & \multirow[t]{2}{*}{0,015} \\
\hline Tidak permisif & 17 & 56,7 & 13 & 43,4 & 30 & 100,0 & \\
\hline \multicolumn{8}{|l|}{ Ibadah dalam keluarga } \\
\hline Tidak mendukung & 22 & 84,6 & 4 & 15,4 & 26 & 100,0 & \multirow{2}{*}{0,021} \\
\hline Mendukung & 14 & 51,9 & 13 & 48,1 & 27 & 100,0 & \\
\hline
\end{tabular}

Sumber: Data Primer, 2015

penelitian. Ditinjau dari segi waktu penelitian ini bersifat cross sectional.

Penelitian ini dilakukan di BNN Kota Surabaya di mana subjek penelitian adalah remaja pengguna NAPZA yang sedang menjalani rehabilitasi rawat jalan di BNN Kota Surabaya.

Populasi dalam penelitian ini sebanyak 56 remaja pengguna NAPZA yang sedang melakukan rehabilitasi dengan menerapkan metode konseling dengan usia 10-19 tahun di BNN Kota Surabaya dan besar sampel didapatkan 53 responden. Teknik pengambilan sampel dilakukan dengan cara simple random sampling. Pengumpulan data di mana sumber data diperoleh melalui data primer dan data sekunder dan analisis data dilakukan dengan menggunakan uji regresi binary logistik.

Pengumpulan data dilakukan dengan cara wawancara berdasarkan panduan kuesioner pada remaja penyalahguna NAPZA di BNN Kota Surabaya yang sedang melakukan rehabilitasi rawat jalan.

Data yang diperoleh kemudian di lakukan pengolahan data dengan cara editing, coding, data entry, dan tabulating setelah di lakukan pengolahan data kemudian di analisis dengan

Tabel 3. Hasil Uji Regresi Binary Logistik Variabel Dominan yang Memengaruhi Penyalahgunaan NAPZA di Wilayah BNN Kota Surabaya

\begin{tabular}{lcccc}
\hline \multicolumn{1}{c}{ Variabel } & B & P $_{\text {value }}$ & RR & CI 95\% \\
\hline Keharmonisan Keluarga & 1,948 & 0,029 & 7,017 & $1,249-30,569$ \\
Aktivitas Orang Tua & 1,451 & 0,093 & 4,266 & $1,163-27,701$ \\
Tipe Orang tua & 2,183 & 0,023 & 8,871 & $1,503-42,591$ \\
Ibadah dalam keluarga & 2,035 & 0,018 & 7,651 & $1,321-31,025$ \\
\hline
\end{tabular}

Sumber: Data Primer, 2015 
menggunakan analisis statistika uji regresi binary logistik.

\section{HASIL PENELITIAN}

Pada penelitian ini terdapat lima variabel lingkungan keluarga, empat variabel memberikan pengaruh dan satu variabel menunjukkan tidak ada pengaruh terhadap penyalahgunaan NAPZA pada remaja di BNN Kota Surabaya. Variabel yang memberikan pengaruh $(\mathrm{Sig}<0,05)$ adalah keharmonisan keluarga, aktivitas orang tua, tipe orang tua dan ibadah dalam keluarga), sedangkan variabel yang tidak berpengaruh terhadap penyalahgunaan NAPZA pada remaja adalah keotoriteran orang tua ( $\mathrm{Sig}>0,05)$. Tabel 2 dan tabel 3 menunjukkan hasil uji regresi binari logistik berdasarkan lingkungan keluarga dengan pemakaian NAPZA pada remaja di BNN Kota Surabaya.

Tabel 2 menunjukkan bahwa hasil uji regresi binari logistik berdasarkan lingkungan keluarga responden terhadap pemakaian NAPZA pada remaja di wilayah BNN Kota Surabaya adalah:

Pola asuh orang tua pada lingkungan keluarga menunjukkan bahwa dari 28 responden pola asuh orang tua yang tidak otoriter sebagian besar adalah kelompok responden yang memakai NAPZA yaitu $71,4 \%$ dibandingkan dengan orang tua yang otoriter hanya $64 \%$. Uji regresi binari logistik menunjukkan bahwa tingkat signifikansi pola asuh orang tua 0,302 yang artinya tidak ada pengaruh penyebab pola asuh orang tua terhadap penyalahgunaan NAPZA pada remaja di BNN Kota Surabaya.

Keharmonisan keluarga pada lingkungan keluarga menunjukkan bahwa dari 31 responden yang memiliki keluarga yang tidak harmonis sebagian besar adalah kelompok responden masih memakai NAPZA yaitu $77,4 \%$ dibandingkan dengan keluarga yang harmonis $54,5 \%$. Uji regresi binari logistik menunjukkan tingkat signifikansi keharmonisan keluarga 0,026 yang artinya ada pengaruh penyebab keharmonisan keluarga terhadap penyalahgunaan NAPZA pada remaja di BNN Kota Suarabaya.

Responden yang memiliki orang tua yang terlalu sibuk sebagian besar adalah kelompok responden yang masih memakai NAPZA yaitu $77,4 \%$ dibandingkan orang tua yang tidak sibuk
$54,5 \%$. Uji regresi binari logistik menunjukkan tingkat signifikansi aktivitas orang tua 0,032 yang artinya ada pengaruh penyebab aktivitas orang tua terhadap penyalahgunaan NAPZA pada remaja di BNN Kota Surabaya.

Responden yang memiliki orang tua permisif sebagian besar menggunakan NAPZA $(82,6 \%)$, presentasi ini lebih kecil jika dibandingkan dengan responden yang orang tuanya tidak permisif $(56,7 \%)$. Uji regresi binari logistik menunjukkan tingkat signifikansi tipe orang tua 0,015 yang artinya ada pengaruh penyebab tipe orang tua terhadap penyalahgunaan NAPZA pada remaja di BNN Kota Surabaya.

Sebagian responden yang tidak taat dalam beribadah adalah kelompok responden masih memakai NAPZA yaitu $84,6 \%$ sedangkan responden yang berasal dari keluarga yang taat beribadah 51,9 \% menggunakan NAPZA. Uji regresi binari logistik menunjukkan tingkat signifikansi ibadah dalam keluarga 0,021 yang artinya ada pengaruh penyebab ibadah dalam keluarga terhadap penyalahgunaan NAPZA pada remaja di BNN Kota Surabaya.

Hasil penelitian menunjukkan bahwa lingkungan keluarga yang paling dominan berpengaruh terhadap penyalahgunaan NAPZA pada remaja adalah ibadah dalam keluarga dengan nilai signifikansi 0,018.

\section{PEMBAHASAN}

Pola asuh otoriter merupakan suatu perilaku yang mengendalikan anak dengan menggunakan hak kekuasaannya (orang tua) dan mengabaikan hak seorang anak sebagai individu untuk dapat menyampaikan pendapatnya (Gunarsa, 2001). Uji regresi binari logistik menunjukkan pola asuh orang tua otoriter tidak berpengaruh terhadap penyalahgunaan NAPZA pada remaja di BNN Kota Surabaya. Sebagian besar pengguna NAPZA mempunyai orang tua yang otoriter.

Pola asuh otoriter yang diterapkan orang tua ditandai dengan cara mengasuh menggunakan aturan yang ketat dan membatasi hak seorang anak untuk dapat melakukan sesuatu serta sering kali memaksa anak untuk berperilaku sesuai dengan keinginan orang tuanya (Hurlock, 2002). 
Menurut teori yang disampaikan Depkes 2001 menyebutkan keotoriteran orang tua tidak bisa menjadi faktor utama dalam penyalahgunaan NAPZA pada remaja, karena masih banyak faktor yang dapat mempengaruhi remaja untuk menyalahgunakan NAPZA yaitu antara lain ketidakharmonisan keluarga, faktor lingkungan sekolah serta lingkungan masyarakat. Latipun (2008), juga mengungkapkan anak yang dibesarkan dengan pola asuh otoriter biasanya akan bersifat tenang, tidak melawan, tidak agresif dan mempunyai tingkah laku yang baik.

Setiap orang akan memiliki respons yang berbeda terhadap menanggapi sesuatu yang ada. Notoatmodjo (2007), mengemukakan bahwa perilaku adalah respons atau reaksi seseorang terhadap stimulus (rangsangan dari luar), dimana dapat dilihat dari bentuk respons tersebut terhadap stimulus dalam bentuk tertutup. Respons terhadap stimulus masih menjadi perhatian persepsi, pengetahuan, atau kesadaran dan sikap pada orang yang menerima stimulus tersebut, dan belum dapat jelas diamati orang lain. Respons yang kedua memiliki bentuk perilaku terbuka yaitu respons seseorang terhadap stimulus dalam bentuk tindakan nyata (terbuka). Respons terhadap stimulus tersebut sudah jelas dalam bentuk tindakan atau praktik, yang dengan mudah dapat diamati atau dilihat oleh orang lain.

Demikian dapat dikatakan bahwa keotoriteran orang tua tidak sepenuhnya menjadi faktor utama penyebab penyalahgunaan NAPZA pada remaja, terdapat faktor lain yang mempengaruhi penyalahgunaan NAPZA. Selain itu respons setiap individu dalam menghadapi sikap orang tua yang otoriter berbeda sehingga tidak hanya memberikan pengaruh negatif tetapi bisa juga memberikan pengaruh positif bagi remaja.

Pengaruh antara keharmonisan keluarga terhadap penyalahgunaan NAPZA pada remaja di BNN Kota Surabaya menjadi penyebab remaja menggunakan NAPZA. Remaja yang memiliki keluarga tidak harmonis berisiko 6,179 kali lebih besar menjadi penyalahguna NAPZA dibandingkan remaja yang memiliki keluarga harmonis.

Kondisi keluarga yang tidak harmonis biasanya sering karena terjadi pertengkaran antar individu (suami-istri atau orang tua-anak) dalam keluarga. Seorang anak akan melihat, mengamati dan memahami apa yang ada di sekitar mereka, sehingga selama terjadi pertengkaran anak akan merasakan kurangnya perhatian dan tidak adanya kedamaian, kehangatan kasih sayang maupun kenyamanan dalam lingkungan keluarga. Akibatnya anak akan lari untuk bisa dapat perhatian dari pihak lain dengan melakukan kenakalan di luar rumah (Dariyo, 2004).

Menurut Sudarsono (2004), menyebutkan keluarga mempunyai peran yang sangat penting dalam memberikan pendidikan dan pembentuk karakter pada anak. Keluarga tidak akan bisa lepas dalam mengasuh seorang anak mulai dari pertumbuhan sampai perkembangan anak dalam keluarga. Sesuai dengan hasil penelitian Rahmadona dan Agustin (2014) juga menyebutkan bahwa peran keluarga memiliki risiko 4,2 kali lebih besar terhadap penyalahguna NAPZA terlebih jika memiliki keluarga yang kurang berperan dalam pencegahan penyalahgunaan NAPZA.

Maria (2007), juga menyebutkan bahwa peran keluarga mempunyai peran tinggi dalam kenakalan remaja. Hasil penelitian ini juga di dukung oleh penelitian Marina (2000), yang menemukan bahwa remaja yang terpenuhinya kebutuhan psikologisnya lebih kecil kecenderungannya terhadap perilaku yang menyimpang salah satunya penyalahgunaan NAPZA. Penelitian Asfriyanti (2003), juga menyebutkan bahwa kenakalan remaja sangat dipengaruhi dari lingkungan keluarga.

Hawari (2009), keutuhan keluarga merupakan salah satu faktor remaja melakukan penyalahgunaan NAPZA, di mana remaja dengan status orang tua tunggal mempunyai pengaruh terhadap gangguan psikologis anak dan permasalahan dalam perilaku yang menyimpang sehingga remaja akan lebih cenderung melakukan penyalahgunaan NAPZA. Penelitian tersebut sependapat dengan penelitian Soetjiningsih (2004), yang menyampaikan bahwa keluarga memiliki pengaruh cukup besar bagi perkembangan anak karena keluarga merupakan lingkungan sosial pertama yang melekat pada dasar kepribadian yang akan dibentuk.

Lingkungan keluarga merupakan yang pertama kali dikenal oleh individu sebagai peranan penting dalam sosialisasi, sehingga 
keluarga yang harmonis akan memberikan contoh teladan bagi seorang anak, karena anak akan menirukan apa yang mereka lihat setiap harinya sehingga apabila keluarga yang tidak harmonis dapat berpengaruh negatif bagi mereka (McMurray, 1994).

Pengaruh antara aktivitas orang tua yang terlalu sibuk terhadap penyalahgunaan NAPZA pada remaja di BNN Kota Surabaya memiliki dampak buruk bagi remaja. Remaja yang memiliki orang tua yang terlalu sibuk akan berisiko 5,677 kali lebih besar menjadi penyalahguna NAPZA dibandingkan responden yang memiliki orang tua perhatian.

Hasil penelitian ini sependapat dengan hasil penelitian Rustyawati (2005), yang menyatakan bahwa kesibukan orang tua berpengaruh terhadap penyalahgunaan NAPZA pada remaja. Hasil penelitian didukung oleh teori Yatim (1990), menyebutkan bahwa kesibukan orang tua yang dilakukan di luar rumah baik karena pekerjaan atau aktivitas masing-masing sehingga sering membuat orang tua pulang larut malam yang dapat memberikan akibat waktu untuk anak akan berkurang sehingga perhatian kepada anak juga akan berkurang.

Kesibukan orang tua yang terlalu padat akan membuat berkurangnya waktu bersama anaknya sehingga akan lupa dengan hak seorang anak untuk mendapatkan kasih sayang dari orang tua. Hal ini akan mempengaruhi baik fisik, mental, maupun sosial emosionalnya, sehingga anak akan cenderung lari dalam pergaulan negatif di luar rumah. Sugiyatno (2010), menyebutkan bahwa frekuensi pertemuan orang tua dengan anak semakin tinggi maka akan semakin besar pengaruh positif kepada anak, karena dengan semakin tinggi frekuensi pertemuan orang tua dengan anak, akan membuat komunikasi orang tua dengan anak akan lebih efektif, sehingga anak akan merasa mendapat perhatian dari orang tua.

Fungsi keluarga yaitu mengajarkan segala sesuatu untuk mempersiapkan anggota keluarga berpengaruh dengan orang lain dan tempat melatih anak untuk dapat bersosialisasi di kalangan yang lebih luas, yakni masyarakat (Suprajitno, 2004).

Menurut Silalahi dan Meinarno (2010), fungsi keluarga memberikan kasih sayang dan cinta serta dukungan emosional kepada anggota keluarganya. Pemberian kasih sayang yang berkelanjutan terhadap anak akan memerikan perkembangan yang efektif tetapi apabila fungsi keluarga tidak dapat diberikan secara efektif, maka akan berdampak pada keeratan dalam keluarga.

Penelitian Brank, Lane, Turner, Fain, dan Sehgal (2008), menyatakan bahwa faktor yang mempengaruhi kenakalan remaja karena penyebab perilaku orang tua dan pengaruh orang tua terhadap anak. Pengaruh orang tua kepada anak dengan memberikan pemantauan lebih besar, yang ditandai dengan mengetahui keberadaan anak mereka atau mengawasi mereka. Aktivitas orang tua mempunyai pengaruh terhadap perilaku anak. Hal ini menunjukkan orang tua yang terlalu sibuk baik karena pekerjaan atau aktivitas masing-masing yang dapat mengakibatkan waktu untuk anak berkurang dalam melakukan pengawasan sehingga perhatian terhadap anaknya juga semakin berkurang (Yatim,1990).

Pengaruh antara tipe orang tua terhadap penyalahgunaan NAPZA pada remaja di BNN Kota Surabaya juga memiliki dampak buruk bagu remaja. Remaja yang memiliki tipe orang tua permisif berisiko 8,001 kali lebih besar menjadi penyalahguna NAPZA dibandingkan responden yang tidak memiliki orang tua permisif.

Tipe orang tua permisif adalah orang tua yang memberikan kebebasan secara penuh kepada anak untuk mengambil keputusan dan melakukannya serta tidak pernah memberikan penjelasan atau pengarahan kepada anak dan hampir tidak pernah ada hukuman atau hadiah, sehingga metode disiplin permisif berarti sedikit disiplin atau tidak ada disiplin. Pola asuh permisif ini di tandai dengan sikap orang tua yang membiarkan anak bebas melakukan apa saja tanpa memberi batasan kepada tingkah laku anak, sehingga anak semua keputusan diserahkan kepada anak tanpa memberi tahu apakah keputusan itu baik atau buruk bagi anak (Hurlock, 2002).

Pengasuh permisif merupakan suatu pola di mana orang tua sangat sangat terlibat dengan remaja, tetapi sedikit sekali orang tua menuntut atau mengendalikan mereka. Pengasuh permisif berkaitan dengan kurangnya pengendalian diri (Santrock, 2003). 
Hasil penelitian Indiyah (2005), yang menyebutkan bahwa ada kecenderungan orang tua yang tidak tegas dan anak bisa berbuat semaunya sebagai faktor penyebab penyalahgunaan NAPZA. Penelitian ini sependapat dengan hasil penelitian Sigelmen (2002), pola asuh permisif mengandung kontrol yang rendah dan responsif yang tinggi. Orang tua yang permisif akan menghasilkan karakteristik anak-anak yang impulsive, agresif, tidak patuh, manja, kurang mandiri, mau menang sendiri, kurang percaya diri, dan kurang matang secara sosial.

Pola asuh orang tua permisif yaitu pola asuh orang tua yang tidak membimbing anak ke pola perilaku yang segala tingkah laku termasuk semua keinginan yang bersifat segera dan tidak menggunakan hukuman. Anak yang tidak diberikan batasan atau kendali yang mengatur, sehingga apa saja yang dilakukan anak dan yang diminta anak boleh dilakukan dan diberikan, mereka dibolehkan mengambil keputusan sendiri sesuai dengan kehendaknya sendiri (Hurlock, 1991).

Pengaruh antara ibadah dalam keluarga terhadap penyalahgunaan NAPZA pada remaja di BNN Kota Surabaya juga merupakan penyebab remaja melakukan penyalahgunaan NAPZA. Remaja yang tidak taat dalam beribadah memiliki risiko 6,401 kali lebih menjadi penyalahguna NAPZA dibandingkan responden yang taat dalam beribadah.

Hasil penelitian Rahmadona dan Agustin (2014), menunjukkan bahwa tingkat religiusitas yang rendah memiliki risiko 175 kali lebih besar menyalahgunakan NAPZA. Hasil penelitian ini sependapat dengan penelitian Muchtar A, dkk (2013), yang menyebutkan bahwa remaja yang memiliki komitmen beragama yang kurang mempunyai risiko 4 kali lebih besar untuk menyalahgunakan NAPZA dibandingkan dengan remaja yang memiliki komitmen beragama yang kuat.

Hasil penelitian sependapat dengan hasil penelitian Rustyawati (2005), yang menyebutkan bahwa individu yang memiliki tingkat religiusitas kurang memiliki risiko 9,1 kali lebih besar terhadap perilaku menyalahgunakan NAPZA. Hawari (2002), bahwa individu yang mempunyai komitmen lemah dan dibesarkan pada keluarga dengan tingkat religiusitas yang rendah mempunyai risiko yang tinggi terhadap penyalahgunaan NAPZA.

\section{KESIMPULAN}

Berdasarkan hasil penelitian dapat diketahui bahwa faktor lingkungan keluarga yang berpengaruh terhadap penyalahgunaan NAPZA pada remaja adalah keharmonisan keluarga $(\mathrm{p}=0,029 ; \mathrm{OR}=7,017 ; \mathrm{CI}=1,249-30,569)$, tipe orang tua $(\mathrm{p}=0,023 ; \mathrm{OR}=8,871 ; \mathrm{CI}=1,503$ $42,591)$, dan ibadah dalam keluarga $(\mathrm{p}=0,018$; $\mathrm{OR}=7,651 ; \mathrm{CI}=1,321-31,025)$. Sedangkan variabel pada lingkungan keluarga yang dominan mempunyai pengaruh terhadap penyalahgunaan NAPZA pada remaja adalah ibadah dalam keluarga $(\mathrm{p}=0,018 ; \mathrm{OR}=7,651$; $\mathrm{CI}=1,321-31,025)$.

Program pencegahan penyalahgunaan NAPZA pada remaja dapat dilakukan melalui sosialisasi di sekolah, yang melibatkan anak didik dan orang tua serta pihak sekolah. Narasumber diperoleh dari mantan pengguna NAPZA serta bekerja sama dengan lembaga yang bersangkutan yaitu BNN agar lebih memahami bahaya dari penyalahgunaan NAPZA. BNN juga dapat melakukan tes urine setiap tiga bulan sekali di sekolah-sekolah agar dapat menindak lanjuti penggunaan NAPZA pada kalangan remaja.

\section{DAFTAR PUSTAKA}

Asfriyanti. 2003. Pengaruh Keluarga Terhadap Kenakalan Anak. Digitized by USU digital library.

Badan Narkotika Nasional. 2006.Peran Remaja Dalam Mengatasi Masalah Penyalahgunaan NAPZA: Mewujudkan Indonesia Bebas dari Ancaman NAPZA. Jakarta: BNN.

Badan Narkotika dan Psikotropika Jawa Timur. 2009. Undang-Undang Republik Indonesia Nomor 35 tahun 2009 tentang Narkotika. Jakarta

Badan Narkotika Nasional. 2012. Jenis-jenis NAPZA dan Aspek Kesehatan Penyalahgunaan NAPZA. Departemen Sosial RI: Jakarta.

Brank, E., Lane, J., Turner, S., Fain, T., and Sehgal, A. 2008. An Experimental Juvenile Probation Program: Effects on Parent and 
Peer Relationships. Crime \& Delinquency. 54(2). pp 193-224

Budiarta T. 2000. Dampak NAPZA dan Upaya Penanggulangannya. Jurnal psikologi. Depok: Universitas Indonesia

Dariyo A. 2004. Psikologi Perkembangan Remaja. Bogor: Ghalia Indonesia.

Depkes RI. 2001. Buku Pedoman Praktis Mengenal Penyalahgunaan NAPZA Secara Terpadu (Pedoman Bagi Keluarga). Jakarta: Depkes RI.

Gunarsa, S. D. 2001. Psikologi Praktis: Anak, Remaja, dan Keluarga. Jakarta: PT. BPK Gunung Mulya

Hawari, D. 2002. Psikologi Perkembangan Anak dan Remaja. Kedokteran Universitas Indonesia

Hawari, D. 2009. Penyalahgunaan dan Ketergantungan NAPZA. Jakarta: Badan Penerbit FKUI.

Hurlock, E.B. 1991. Child Development.6th.Ed. (Alih Bahasa oleh Tjandarsa, M; dan Zarkasih, M.) Jakarta: PT. Gelora Aksara Pratama

Hurlock, E.B. 2002. Psikologi Perkembangan, Edisi Kelima. Jakarta: Erlangga.

Kurniasih N. 2014. Buletin Jendela: Pengguna NAPZA Dapat Dicegah dan Dapat Direhabilitasi. Jakarta: Kementrian Kesehatan RI.

Latipun. 2008. Psikologi Konseling Edisi Ketiga. Malang: UPT Penerbit Universitas Muhammadiyah Malag

Maria, U. 2007. Peran Persepsi Keharmonisan Keluarga dan Konsep Diri terhadap Kecenderungan Kenakalan Remaja. Tesis: Universitas Gadjah M ada

Marina. 2000.Hubungan antara Tipe Kepribadian Introvert-Ekstrovent dan Tingkah laku Penyalahgunaan Heroin pada Remaja. Jurnal psikologi

McMurray, D.M., Prokhorov, A.V. \& Harty, K.C. (1994). Effects of a statewide antismoking campaign onmass-media messages and smoking beliefs. Prev Med. 23(1). pp 54-60
Muchtar, A. et al. 2013. Faktor Berhubungan dengan Penyalahguna Narkotika dan Bahan Adiktif (NAPZA) pada Remaja di SMA Kartika Wirabuana XX-I Makassar tahun 2013: Jurnal. Universitas Hassanudin.

Notoatmodjo, S. 2007. Promosi Kesehatan dan Ilmu Perilaku. Jakarta: Renika Cipta.

Rahmadona E, Agustin H. 2014. Faktor yang Berhubungan dengan Penyalahguna NAPZA di RSJ Prof. Hb Sa'anin. Vol.8, No.2, Hal 59-65,

Rustyawati. 2005.Beberapa Faktor Risiko yang Berhubungan dengan Penyalahgunaan NAPZA pada Penderita yang di Rawat di Rehabilitasi (Studi Kasus di Semarang dan Sekitar).

Santrock, J. W. 2003. Adolescence: Perkembangan Remaja. Jakarta: Erlangga

Sigelman, C.k., Rider, E.A. 2006. Life Span Human Development. (5thed.). Canada: Thompson Wadsworth p.431

Silalahi K dan Meinarno E.A. 2010. Keluarga Indonesia Aspek dan Dinamika Zaman. Jakarta: Rajagrafindo Persada.

Soetjingsih. 2004.Tumbuh Kembang Anak. Jakarta: EGC

Sudarsono. 2004.Kenakalan Remaja. Jakarta: Rineka Cipta

Sugiyatno. 2010. Optimalisasi Peran Keluarga dalam Membangun Moral Anak. Dinamika Pendidikan No. 01/Th.XVII

Suprajitno. 2004.Asuhan Keperawatan Keluarga Aplikasi dalam Praktik. Jakarta: EGC.

Waluyo B. 2011. Viktimologi Perlindungan Hukum Terhadap Korban Kejahatan, Sinar Grafika.

Yatim D. 1990.Kepribadian Keluarga \& Narkotika, Tinjauan Sosial Psikologis. Jakarta: Arcan

Yusuf S. 2009. Psikologi Perkembangan Anak dan Remaja. Bandung: Rosda Karya. 